\title{
Correction to: Ficus sycomorus extract reversed behavioral impairment and brain oxidative stress induced by unpredictable chronic mild stress in rats
}

Harquin Simplice Foyet ${ }^{1 *}$, Serge Tchinda Deffo ${ }^{2}$, Pascaline Koagne Yewo ${ }^{2}$, Iulia Antioch ${ }^{3}$, Stéphane Zingue ${ }^{2}$, Emmanuel Acha Asongalem ${ }^{4}$, Pierre Kamtchouing ${ }^{5}$ and Alin Ciobica ${ }^{3}$

\section{Correction}

After the publication of this article [1] it came to our attention that Harquin Simplice Foyet was incorrectly included as Harquin Simplice Harquin Foyet. The corrected name is included in the author list. The original article was updated.

\begin{abstract}
Author details
'Department of Biological Sciences, Faculty of Science, University of Maroua, Cameroon, P.O. Box: 814, Maroua, Cameroon. ${ }^{2}$ Department of Life and Earth Sciences, Higher Teachers' Training College, University of Maroua, Cameron, P.O. Box: 55, Maroua, Cameroon. ${ }^{3}$ Department of Research, Faculty of

Biology, Alexandru loan Cuza University, 11 Carol I Blvd, 700506 lasi, Romania. ${ }^{4}$ Department of Biomedical Sciences, Faculty of Health Sciences, University of Buea, Cameroon, P.O. Box 63, Buea, Cameroon. ${ }^{5}$ Department of Animal Biology and physiology, Faculty of Science, University of Yaounde I, Yaounde, Cameroon.
\end{abstract}

Received: 4 December 2017 Accepted: 19 December 2017

Published online: 28 December 2017

\section{Reference}

1. Foyet $\mathrm{HS}$, et al. Ficus sycomorus extract reversed behavioral impairment and brain oxidative stress induced by unpredictable chronic mild stress in rats. BMC Complement Altern Med. 2017;17:502. doi: 10.1186/s12906-017-2012-9.

\footnotetext{
*Correspondence: fharquins@gmail.com; simplice-harquin.foyet@fs.univmaroua.cm

'Department of Biological Sciences, Faculty of Science, University of Maroua, Cameroon, P.O. Box: 814, Maroua, Cameroon

Full list of author information is available at the end of the article
} 